\title{
Carers as partners in mental health services for older people
}

\author{
Jan R. Oyebode
}

\begin{abstract}
The role that carers play in supporting older people with mental health needs in the community is well recognised by professionals and in current government policy. This article promotes the view that a systematic planned approach that engages the carer as an integral part of the system of care has potential benefits for patients, carers and services. Ways of working in partnership are outlined and evidence that psychosocial interventions with carers are effective is briefly reviewed. Examples of individual and group interventions for dementia carers are given, drawing on clinical experience and research literature. Areas for further development are highlighted, including greater partnerships with carers in primary and continuing care, as well as at the level of planning and service development.
\end{abstract}

Many of us as we age will need help with some aspect of our lives, with this being perhaps the most far-reaching for those who develop dementia. The numbers needing support will continue to rise as the older population increases. People over 85 years old now make up almost $2 \%$ of the UK population and this is projected to increase to almost $4 \%$ by 2031 (Office for National Statistics, 2001). Up to $25 \%$ of this age group may be expected to develop dementia, and thus the needs for care and support are considerable. Most of those who need help with their day-to-day lives are supported by relatives. Data from the most recent census indicate that about 1 in 10 people in the population are providing unpaid care (Office for National Statistics, 2001). It therefore follows that developing constructive working relationships with carers needs to be a key element of service provision for older people with mental health difficulties who require and receive care from their partner or family.

Recent government policy and health and social service strategy recognise this imperative. The National Strategy for Carers (Department of Health, 1999b: p. 13) talks about providing information for carers 'so that they become real partners in the provision of care to the person they are looking after'. The National Service Framework (NSF) for Older People (Department of Health, 2001) also recognises the role of relatives in mental health care. Standard 7 states:
'Older people who have mental health problems have access to integrated mental health services, provided by the NHS and councils to ensure effective diagnosis, treatment and support, for them and for their carers' (my italics).

In addition, given Standard 1 of the Older People's NSF, which states a commitment to rooting out ageism, carers should be entitled also to the provisions for carers made in Standard 6 of the NSF for Mental Health (Department of Health, 1999a).

The majority of carers would prefer to continue, with appropriate support, rather than relinquish care to others. Indeed, a recent survey of carers of people with dementia, mental health problems or learning disabilities found that the greatest fear expressed by the 1000 or so respondents was of what might happen should they die or become too ill to continue to provide care (Princess Royal Trust for Carers, 2004). In addition, recent studies with non-cognitively impaired participants receiving informal care have shown that the perceived quality of the care and the relationship with their carer have a greater influence on wellbeing than does their actual health (Martire et al, 2003; Wolff \& Agree, 2004). Thus, collaborative and supportive partnership is important for those receiving care and is a goal held by carers and emphasised by carers' organisations, as well as being a current theme in government policy and statutory services.

Jan Oyebode is a clinical psychologist specialising in work with older people. She is a senior lecturer and Director of the Clinical Psychology Doctorate Course at the University of Birmingham (School of Psychology, University of Birmingham, Edgbaston, Birmingham B15 2TT, UK. E-mail: j.r.oyebode@bham.ac.uk) and spends one day a week in clinical practice within Birmingham and Solihull Mental Health NHS Trust. Her particular interests are in psychological adaptation to late-life events, including dementia and bereavement. 


\section{Box 1 Officialdom}

'Officialdom is only really helpful in theory. In practice, it's illogical, time-consuming, obscure, usually demeaning, often unproductive and always unpredictable.' [p. 94]

'It's complex, faceless, unable to make allowances for human individuality or leaps of logic, slow to change course, and incapable of empathising.' [p. 97]

(Marriott, 2003)

However, despite the good intentions of government policy and of service providers, carers do not always feel welcomed, understood and supported by services, as Marriott's comments on the topic of officialdom illustrate (Box 1).

In this article I draw on my own clinical experience and published research evidence to stimulate thinking about how professionals can ensure that mental health services for older people establish sound partnerships with their patients and carers. Evaluation of the extensive literature for the effectiveness of carer interventions has been drawn together by recent researchers in meta-analyses and reviews. Those quoted here and examples of recent studies have been drawn from searches of Medline and PsychInfo databases.

\section{Ideal partnerships}

The possibilities for partnership with carers may be imagined as lying on a continuum, stretching from, at one end, the focus of services solely on the patient through to, at the other end, a true partnership in which the patient, the carer and the services are truly working together towards shared goals. The gold standard is a situation in which the care recipient and their significant other/s are at the centre of assessment, care-planning and intervention. Since their mutual well-being depends on each other, it is not possible to design effective care plans that consider the patient only, as the roles and needs of both in the relationship have to be taken into account.

The following description attempts to operationalise this ideal from the point of view of a service providing for a person with dementia.

\section{Case example}

Mrs Smith was diagnosed with dementia. Following referral by her general practitioner, the mental health team, as part of its initial assessment, established whether there was anyone within the family who was or potentially might be involved in her support. It was found that her primary carer was her husband, and Mrs Smith was asked to give her consent for him to be involved in her assessment and care-planning. Thus, the aim of her initial assessment was not only to gain an understanding of her diagnosis and needs, but also to take into account her carer's current roles, concerns and needs.

Mr Smith was firm in wanting to continue caring for his wife at home, but he was worried about the practicalities of this. He knew little about dementia and wanted to know how best he could help his wife to live with it. A care plan was prepared that would ameliorate Mrs Smith's situation, but that also took into account Mr Smith's wish to continue taking care of his wife. The plan included support for both Mr and Mrs Smith that maintained their well-being at home. Mr Smith was given leaflets about dementia, which he later discussed with a mental health nurse, and was put into contact with a local dementia support group. He was offered home-help visits, should he find caring for both his wife and their house too much.

This type of framework is described in a North American primary care context by Burns et al (2003), who give a useful example of the blueprint they use to establish needs for carer support. It is also quite close to the model described in Standard 6 of the NSF for Mental Health (Department of Health, 1999a), which envisages carers having an assessment of their caring, physical and mental health needs and a care plan that is reviewed at least annually.

There are many positions in between this ideal and a service focusing only on the patient. Most services will ensure that they gather assessment material from a close relative who is able to give information that might not be provided by a patient with memory problems. The diagnosis is commonly disclosed to the relative (sometimes to the exclusion of the patient, as may be the case for dementia) (Bamford et al, 2004). It is fairly common, particularly in memory clinics, for the significant other to be offered a follow-up session from someone in the team in order to provide further information. Carers may also be invited to review meetings or out-patient appointments. Many services offer carers the opportunity to attend groups that provide information about ways of coping and a chance to gain mutual support. Where relatives are under strain, it is common for services to offer respite through day or short-stay care. Less commonly, carers may be explicitly taught skills to use in helping a relative with, for example, dementia. These might include communication skills, behavioural management techniques, cognitive rehabilitation techniques or skills to help maintain personhood. Thus, we can see that carers may be treated as informants, proxies for the patient, patients themselves, requiring support to relieve stress, or as co-therapists who require education and training. 
Currently, services offer what they have available but often in an ad hoc rather than a planned manner. They may react to carers who are struggling and try to give them breathing space, but they do not necessarily plan with carers, proactively, ways to cope effectively with their caregiving role and protect their own sense of well-being. Opportunities to enable the caregiving role to continue in a more satisfactory manner for both care recipient and carer may be missed. Very often, and especially where the carer is not reporting stress, routine follow-up is carried out by a member of a multidisciplinary team through home visits to check that the patient is managing. The carer, particularly one who is not coresident, might not even be interviewed. This may leave carers feeling that their input is taken for granted or that they are viewed as peripheral to the illness and its management.

A systematic planned approach that engages the carer as an integral part of the system has potential benefits for patients, carers and services. However, this can demand a shift in thinking, especially for health service professionals, as we may conceive of our role as locating pathology within the individual and ameliorating this through treatment delivered to that individual.

\section{Effectiveness of interventions}

It can be hard to demonstrate that interventions with carers make a difference to outcome for the carer or the care recipient. This is partly because discrete carer interventions tend to take place alongside a package of other services. So, for example, isolating the impact of a carers' group to establish its effectiveness may be made difficult by the fact that other elements of care such as anticholinesterase inhibitors and day care were introduced at the same time. Many studies look for changes in proximal indicators related to carers' mental health, such as level of depression, anxiety or carer burden. However, the stressors usually continue to be present, and feelings of burden, unhappiness and anxiety may be an understandable response to such a situation. Gottlieb et al (2003), discussing dementia carers, have suggested that it is more appropriate to find out whether the carers feel validated and accepted than to look for improvements in mental health symptoms (Box 2). Others have followed up samples over time to look at meaningful long-term outcomes, for example in rates of care-recipient institutionalisation or mortality (Brodaty et al, 1997).

Among reviews of the effectiveness of interventions for carers of people with dementia are those by Brodaty et al (2003), Schulz et al (2002), Cuijpers \& Nies (1997) and Knight et al (1993). Knight et al's meta-analysis, covering the period 1980-1990, and
Box 2 Evaluating interventions for carers (Gottlieb et al, 2003)

Three domains should be examined to find out whether a carer intervention is successful:

- whether the carer believes that the person for whom they care is better off as a result of the intervention

- whether the carer feels that they are handling their role as well as possible (i.e. have a sense of self-efficacy)

- whether the carer feels that they are coping better with their own reactions

Cuijpers \& Nies' review, covering 1985-1993, both suggested that individual psychosocial interventions have positive effects. Knight also found evidence that respite care yields a moderate benefit, although Cuijpers \& Nies concluded that it has little effect. Both found some evidence that psychosocial group interventions lead to modest benefits.

Schulz et al (2002) examined studies conducted between 1996 and 2001 of carer interventions, environmental interventions and pharmacological treatments for care recipients with dementia. They examined outcome in four domains: symptoms of carer physical or mental ill health, social significance (including resource consequences in terms of service use and time to institutionalisation), carer quality of life and the social acceptability of the interventions to the carer and care recipient. They found that psychosocial interventions for carers showed significant small-to-moderate benefits in the domains of carer mental health, social significance and social acceptability.

Brodaty et al's 2003 meta-analysis was based on controlled trials of dementia carer interventions, excluding respite care, reported between 1985 and 2001. They found that there were significant benefits across the 30 studies they located in terms of improved psychological distress levels and knowledge in the carer as well as mood of the care recipient. In four of the seven studies which examined it, there was a delay in time to institutionalisation. There was no impact on carer burden. It may seem paradoxical that carer burden remains while carers' mental health improves. However, it may be that, although objective burden remains or becomes heavier, it is unrealistic to expect that there will be measurable relief in feelings of strain relating to caregiving, but it is possible to ameliorate the more pervasive aspects of depression.

These four well-conducted reviews therefore indicate that there are measurable benefits from working with carers, both for the carers themselves and for care recipients with dementia. 


\section{Types of intervention}

In their 1997 review, Cuijpers \& Nies divided interventions for carers into three groups: information, consultation and emotional support; respite care; and individual psychosocial interventions. Zarit \& Edwards (1999) distinguish between treatment strategies (information, problem-solving and support) and modalities (counselling, family meetings and support groups). In the next section, I briefly describe ways of working in partnership with carers, distinguishing between the level of the intervention (individual or group) and giving information about whether each aims to provide information, support or skills.

\section{Individual interventions}

The advantage of individual interventions is that they can be tailored to issues relevant to the specific situation of each care recipient and carer. Reviews in the field of dementia care suggest that individual psychosocial interventions provide the most effective way of generating gains for both carer and care recipient (see above).

\section{Intensive case management}

In dementia care, intensive case management (Challis et al, 2002), which pays close attention to the needs of care recipient and carer and provides a responsive service, has been shown to have benefits above and beyond those from usual multidisciplinary team services. Challis et al found that care recipients who had received the case management approach had reduced need, were at less risk of coming to harm, showed improvement in activities of daily living and had a greater number of social contacts than those who had not. Carers felt less stressed and had to do less for the care recipients. By the end of the second year of the study, $51 \%$ of care recipients in the case management group were still at home, compared with $33 \%$ of those who received the usual services.

\section{Cognitive-behavioural family intervention}

Marriot et al (2000) provide an excellent example of an individually tailored yet structured intervention for carers, based on a stress vulnerability model, which aimed to reduce burden in carers and gain benefit for care recipients with Alzheimer's disease. It is described as a cognitive-behavioural family intervention and involved an in-depth assessment of the needs of both the care recipient and their principle carer, leading to 14 fortnightly sessions with the carer, which included the provision of information and teaching of stress management and coping skills. A randomised controlled trial evaluating the intervention found that the carers in the intervention group had lower levels of psychological morbidity and depression than controls at 3-month follow-up, and that the care recipients in the intervention group showed an increase in activities of daily living.

\section{Cognitive rehabilitation}

A developing area in the field of dementia care is that of cognitive rehabilitation (Clare \& Woods, 2001) and this holds great potential for working in partnership with carers. The carer can be involved as a therapist working on retention or enhancement of skills with the care recipient. Such joint working has been found to have positive effects on interaction between the couple (Quayhagen \& Quayhagen, 1996) and in addition on the care recipient's cognitive functioning both immediately and at 3 months post intervention (Quayhagen \& Quayhagen, 2001). The authors describe two studies with samples of 56 and 30 dyads, respectively, of a person with dementia and their spouse. The couples spent $1 \mathrm{~h}$ a day, 5 days a week working on cognitive rehabilitation tasks. The first study was a 12-week intervention with separate sessions focusing on memory, communication and problem-solving; the second intervention lasted 8 weeks and each session included all three of these areas. Both studies found a positive effect on aspects of cognitive functioning compared with control groups.

\section{Group interventions}

Group interventions are attractive in providing a way of cutting through the isolation experienced by many carers. They are also more efficient in terms of professional time, although this may to be at the cost of effectiveness, as they do not have as positive an effect as the individual interventions mentioned above.

Carer support groups are among the most widely available resources for carers and take a range of forms to target different needs. In dementia care, the most common are closed, time-limited groups and open-ended, open-access groups.

The closed, time-limited groups, usually professionally facilitated, provide psychoeducation and support for carers whose relative has early dementia or who has just received a diagnosis. The open-ended groups can be attended by anyone in a certain 
Box 3 Key features of the Birmingham and Solihull Mental Health Trust programme for dementia carers

- Participants can join either a day-time or an early-evening group; this suits both spousal carers, who usually prefer not to come out in the evenings, and adult children who are at work during the day

- All potential participants are visited at home by one of the facilitators or associated staff to establish need and provide a familiar face at the first meeting

- Free taxi transport is provided if required, and an effort is made to hold the meetings where parking is easy

- Care recipients can come with their carers and they pursue an activity of their own in another room, with support from a member of staff

- The programme itself focuses for about half the meetings on the caring role and for about half on the carers' own needs

- A lengthy break for refreshments allows carers, care recipients and facilitators to mix in a more informal way

- Each group is run by two facilitators from differing professional backgrounds (usually a nurse and a clinical psychologist) and the same facilitators attend throughout the 6-week programme (a social worker with good knowledge of financial and legal matters also attends the penultimate meeting)

catchment area or who has relatives in a particular facility; these provide ongoing support. The latter are often professionally supported, but may be run on a self-help basis.

Closed, time-limited groups have received more attention in terms of evaluation of their impact and have been found to have small, positive benefits (see Knight et al, 1993; Cuijpers \& Nies, 1997; Schulz et al, 2002; Brodaty et al, 2003). Groups of this type for the primary carers (relative, neighbour or friend) of anyone recently diagnosed with dementia in the Birmingham and Solihull Mental Health Trust have been running for the past 8 years using a 6-week programme. Box 3 shows aspects of the programme that appear important to carer satisfaction and benefit from the groups. Although there has not been controlled evaluation, attendance levels and followup interviews indicate satisfaction and benefit especially in reducing isolation, gaining information and sharing ideas for caring.
Brodaty and colleagues (Brodaty \& Gresham, 1989; Brodaty \& Peters, 1991; Brodaty et al, 1997) describe a variant on a carers' group. They delivered and evaluated a 10-day residential programme with regular follow-up meetings and telephone calls over 12 months, for care recipients with dementia and their co-resident carers, mainly spouses. The programme had a number of elements for carers, including provision of information, skills training, group and family therapy and activities. The care recipients had sessions in memory retraining, reminiscence therapy and general activities. Impressively, there were two control groups. One of these was a 6-month waiting-list group, and in the the other the care recipients received their part of the programme, but there was no input for the carers. At 8-year follow-up, the care recipients whose carers had received the training were found to have stayed at home significantly longer: $70 \%$ of those in the treated groups had been admitted to nursing home care compared with $81 \%$ of the controls. They also tended to live longer than did those whose carers had not had the training ( $58 \%$ v. $70 \%$ mortality).

It is not entirely clear which elements of carers' groups provide the therapeutic benefit and it may be the combination of elements that is particularly helpful. However, there is some evidence that information alone does not produce change in the well-being of carers or care recipients (Marriott et al, 2001) and that skills-based training is more effective (Coon et al, 2003).

\section{Partnerships with primary care}

The information above focuses on working with carers during the period following referral to a specialist mental health service and while the carer is supporting the care recipient in their own home. There are also opportunities for mental health services to promote partnerships earlier and later in the episode of care. General practitioners are usually the first port of call for patients and relatives concerned about mental health. However, dementia is not always routinely diagnosed in primary care and may only be revealed when there is a crisis. In a review of reasons for the delay in recognition of dementia in primary care, Iliffe (1997) suggests that primary care workers need better diagnostic skills, more knowledge about interventions and contacts with networks of local mental health agencies who are involved with dementia care. Outreach from older people's mental health services to primary care would seem essential to enable people with dementia and their carers to get the information and support they need when problems are still at an early stage. Primary mental health workers specifically for older people's services can help to bridge this gap. 


\section{Partnerships between carers and institutions}

One area that appears important to those with dementia and also to relatives is the need to maintain the personal identity of the ill person (Kitwood, 1997; Cheston \& Bender, 1999; Perry \& O'Connor, 2002). While individuals remain in their own homes they are in familiar surroundings and are usually cared for by those who know them intimately. However, when they move into institutional care and leave familiar people and things behind, maintaining identity often becomes a major issue. There has been extensive research into interventions that may improve quality of life for those with dementia who are in care. However, there seems to be no research on the ways carers might continue to be involved and on the potential impact of this. This is an area that would benefit from development and evaluation.

\section{Barriers to working in partnership}

Collaborative working with older people and their carers in pursuit of a common goal sounds a straightforward aim, even if hard work is required to see it through. However, there may be tensions and ethical dilemmas that demand attention. Within the triad of relationships between patients, carers and professionals there can be differences in understanding, approach and desired outcomes. These are not always explicit but require careful consideration. So, for example, a person with dementia may have a strong preference for remaining in their own home, but their carer may feel that risk to the ill person or their own exhaustion leave no alternative to admission to institutional care. Healthcare services will tend to side with one or the other of these positions, and providers must therefore examine their own preconceived ideas, in order to be supportive in working with both to find a negotiated solution.

Dilemmas may be more acute when the care is taking place in a context of an ambivalent relationship. A spouse or adult child who has been abused by the person for whom they are expected to provide care may find it hard to give that care, but just as hard to disclose why to care professionals. Professionals may therefore need to take the lead in asking about the nature of the past relationship, which is the backdrop against which dependence and care have developed. Furthermore, carers themselves do not always have benevolent motives. For example, family members may plan the future with a view to retaining as much of their inheritance as possible, rather than thinking primarily of the quality of life of a care recipient. These issues stress the importance of early assessment not only of the patient but also of the carers' perspective and needs. The best way forward for each specific case should be considered with the well-being of the patient in mind, but also appreciating the costs to carers. Systemic approaches, with their emphasis on deriving understanding from multiple layers of context, may help all parties to work together in their search for ways of managing.

\section{Partnerships for service planning}

Much research and service in this area is focused on the dyad of the care recipient and carer. However, in developing broader partnerships it is helpful to consider a range of levels, including the wider family, community and country (Thompson et al, 2003). Research and development focused on ways of working with the care recipient/carer dyad must continue, but services might also consider working with the wider informal support network that is available to the couple.

Rising above the individual case, there is great potential in the development by statutory services of formal consultative links with carers and service users. Voluntary organisations focusing on carers or issues of old age, such as the Princess Royal Trust for Carers, the Alzheimer's Society and Age Concern, may be partners in policy development and service planning. Indeed, health authorities should already have made provision for involving older people and carers in the implementation of the Older People's NSF standards. The Alzheimer's Society (2002) has collated advice that can be used by their local groups to influence implementation of the Older People's NSF and they report that some local implementation teams are using Alzheimer's Society branches as 'user reference groups'. The Princess Royal Trust for Carers has been involved in a partnership initiative, 'Partners in Care', with the Royal College of Psychiatrists to raise awareness and bridge gaps between professionals and members of the public in their perceptions of dementia (http://www. partnersincare.co.uk). Outreach to community and voluntary groups representing diverse cultural communities may allow development of culturally sensitive support for Black and minority ethnic groups.

\section{Conclusions}

Satisfactory care for older people with mental health problems, especially dementia, depends on the goodwill and skills of informal carers. Embracing carers as an integral part of the system and also recognising that they may have needs in their own right can have positive consequences for patients, 
carers and services. Research evidence shows that comprehensive, intensive, individually tailored interventions can have an impact on carer well-being, the functioning of the care recipient and the relationship of the dyad. Both individual and intensive group interventions can reduce time to institutionalisation. Working in partnership with carers demands a shift in thinking for health service professionals as we may conceive of our role as identifying the pathology within the individual and treating this through biomedical approaches. However, systemic aspects of care and psychosocial interventions can make equally powerful contributions to the well-being of older people with mental health difficulties.

\section{References}

Alzheimer's Society (2002) Let's Make it Happen: The National Service Framework for Older People. London: Alzheimer's Society.

Bamford, C., Lamont, S., Eccles, M., et al (2004) Disclosing a diagnosis of dementia: a systematic review. International Journal of Geriatric Psychiatry, 19, 151-169.

Brodaty, H. \& Gresham, M. (1989) Effect of a training programme to reduce stress in carers of people with dementia. BMJ, 299, 1375-1379.

Brodaty, H. \& Peters, K. (1991) Cost effectiveness of a training program for dementia carers. International Psychogeriatrics, 3, 11-22.

Brodaty, H, Gresham, M. \& Luscombe, G. (1997) The Prince Henry Hospital dementia caregivers' training programme. International Journal of Geriatric Psychiatry, 12, 183-192.

Brodaty, H., Green, A. \& Koschera, A. (2003) Meta-analysis of psychosocial interventions for caregivers of people with dementia. Journal of the American Geriatrics Society, 51, 657664

Burns, R., Nichols, L., Martindale-Adams, J., et al (2003) Primary care: partnering with health care providers. In Innovative Interventions to Reduce Dementia Caregiver Distress: A Clinical Guide (eds D. Coon, D. GallagherThompson \& L. Thompson). New York: Springer.

Challis, D., von-Abendorff, R., Brown, P., et al (2002) Care management, dementia care and specialist mental health services: an evaluation. International Journal of Geriatric Psychiatry, 17, 315-325.

Cheston, R. \& Bender, M. (1999) Understanding Dementia: The Man with the Worried Eyes. London: Jessica Kingsley.

Clare, L. \& Woods, R. (2001) Cognitive Rehabilitation in Dementia. Hove: Psychology Press.

Coon, D., Thompson, L., Steffen, A., et al (2003) Anger and depression management: psychoeducational skill training interventions for women caregivers of a relative with dementia. Gerontologist, 43, 678-689.

Cuijpers, P. \& Nies, H. (1997) Supporting informal caregivers of demented elderly people: psychosocial interventions and their outcomes. In Caregiving in Dementia: Research and Applications (eds B. Miesen \& G. Jones) London: Routledge.

Department of Health (1999a) National Service Framework for Mental Health. London: Stationery Office.

Department of Health (1999b) The National Strategy for Carers. London: Stationery Office.

Department of Health (2001) National Service Framework for Older People. London: Stationery Office

Gottlieb, B., Thompson, L. \& Bourgeois, M. (2003) Monitoring and evaluating interventions. In Innovative Interventions to Reduce Dementia Caregiver Distress: A Clinical Guide (eds D. Coon, D. Gallagher-Thompson \& L. Thompson). New York: Springer.

Iliffe, S. (1997) Can delays in the recognition of dementia in primary care be avoided? Aging and Mental Health, 1, 7-10.
Kitwood, T. (1997) Dementia Reconsidered: The Person Comes First. Milton Keynes: Open University Press.

Knight, B., Lutsky, S. \& Macofsky-Urban, F. (1993) A metaanalytic review of interventions for caregiver distress: recommendations for future research. Gerontologist, 33, $240-248$

Marriott, A., Donaldson, C., Tarrier, N., et al (2000) Effectiveness of cognitive-behavioural family intervention in reducing the burden of care in carers of patients with Alzheimer's disease. British Journal of Psychiatry, 176, 557562

Marriott, A., Tarrier, N. \& Burns A (2001) Authors' reply to Information and education for carers of patients with Alzheimer's disease. British Journal of Psychiatry, 178, 8384.

Marriott, H. (2003) The Selfish Pig's Guide to Caring. Cliftonupon-Teme: Polperro Heritage Press.

Martire, L., Schulz. R., Wrosch. C et al (2003) Perceptions and implications of received spousal care: evidence from the Caregiver Health Effects Study. Psychology and Aging, 18, 593-601.

Office for National Statistics (2001) Census 2001. http:// www.statistics.gov.uk/Census2001

Perry, J. \& O'Connor, D. (2002) Preserving personhood: remembering the spouse with dementia. Family Relations: Interdisciplinary Journal of Applied Family Studies, 51, 5562.

Princess Royal Trust for Carers (2004) Survey Finds Carers Suffer from Stress and Anxiety. http://www.rcpsych.ac.uk/ press/preleases/pr/pr_512.htm

Quayhagen, M. P. \& Quayhagen, M. (1996) Discovering life quality in coping with dementia. Western Journal of Nursing, 18, 120-135.

Quayhagen, M. P. \& Quayhagen, M. (2001) Testing of a cognitive stimulation intervention for dementia caregiving dyads. In Cognitive Rehabilitation in Dementia (eds L. Clare \& R. T. Woods). Hove: Psychology Press.

Schulz, R., O'Brien, A., Czaja, S., et al (2002) Dementia caregiver intervention research: in search of clinical significance. Gerontologist, 42, 589-602.

Thompson, L., Gallagher-Thompson, D. \& Haley, W. (2003) Future directions in dementia caregiving research and practice. Innovative Interventions to Reduce Dementia Caregiver Distress: A Clinical Guide (eds D. Coon, D. Gallagher-Thompson \& L. Thompson). New York: Springer.

Wolff, J. L. \& Agree, E. M. (2004) Depression among recipients of informal care: the effects of reciprocity, respect, and adequacy of support. Journal of Gerontology: Psychological Sciences and Social Sciences, 59, S173-S180.

Zarit, S. \& Edwards, A. (1999) Family caregiving: research and clinical intervention. In Psychological Problems of Ageing: Assessment, Treatment and Care (ed. R. T. Woods). Chichester: John Wiley \& Sons.

\section{MCQs}

1 Partnership between services and carers includes:

a finding out about a carer's roles, concerns and needs

$\mathrm{b}$ disclosing the diagnosis to the carer rather than the patient

c providing information for carers as necessary

$\mathrm{d}$ encouraging all carers to use respite care for the patient

e proactively planning ways to meet carer needs as well as patient needs.

2 Aspects of partnership may include:

a offering a carer an opportunity to attend a carers' group 
$\mathrm{b}$ offering a carer training in behaviour management

c advising carers that cognitive rehabilitation should be left to the professionals

$\mathrm{d}$ ensuring that follow-up appointments are with the patient alone

e offering group, family or individual interventions.

3 Regarding the effectiveness of interventions:

a group interventions for carers are generally more effective than individual interventions

b cognitive-behavioural therapy for carers can lead to improved functioning of the care recipient

c intensive carer support can delay institutionalisation of the care recipient

d carer-led cognitive rehabilitation can lead to improved cognitive functioning in people with dementia

e respite care generally has more impact than other psychosocial interventions.
4 In consideration of ethical issues, it should be remembered that:

a carers always know what is best for a relative with dementia

b carers may sometimes exploit a relative for material gain

c services should put the needs of the carer first

d previously abusive relationships should not be taken into account in deciding patient needs

e services always know what is best.

5 Future developments may include:

a outreach from older people's mental health services to primary care

$\mathrm{b}$ avoiding carer involvement in service development

c greater involvement of carers in institutional care

d greater involvement of carers in service planning

e avoiding partnerships with the voluntary sector. 